\title{
REVISIONES
}

\section{El pasado reciente en la experiencia chilena. Bases para una pedagogía de la memoria*}

\author{
Recent past in the chilean experience. Grounds for the pedagogy of memory
}

O passado recente na experiência chilena. Bases para a pedagogia da memória

\author{
Graciela Rubio
}

Universidad Andrés Bello. Correo electrónico: ariadna@vtr.net

\section{RESUMEN}

Se reflexiona sobre el pasado reciente como experiencia histórica, objeto de estudio, elaboración discursiva y sus perspectivas de enseñabilidad en Chile. Se propone una pedagogía hermenéutica crítica y narrativa que oriente el aprendizaje de dicho pasado desde una memoria reflexiva.

Palabras clave: pasado reciente, memoria histórica, pedagogía de la memoria.

\section{ABSTRACT}

A reflection about the recent past can be seen as historical experience, object of study, discursive building up and its perspectives of teaching in Chile. A critical and narrative hermeneutic pedagogy is proposed to direct the learning of that past from a reflexive memory.

Key words: the recent past, historical memory, pedagogy.

\section{RESUMO}

Repensa-se o passado recente, como experiência histórica, objeto de estudo, elaboração discursiva e suas perspectivas de ensino no Chile. Propõe-se uma pedagogia hermenêutico-crítica e narrativa que orienta a aprendizagem de tal passado desde uma memória reflexiva.

Palavras chave: passado recente, memória histórica, pedagogia da memória.

\footnotetext{
* Se presentan algunos aspectos relevantes extraídos de la investigación doctoral: Memoria y pasado reciente en la experiencia chilena: Hacia una pedagogía de la memoria. Rubio Graciela. (2010) Departamento de Didáctica y Organización Escolar. Universidad de Granada.
} 


\section{INTRODUCCIÓN}

En el último tiempo la categoría temporal pasado reciente se ha venido consolidando como un campo específico de la investigación histórica y social. La necesidad de conceptualizar las experiencias de sufrimiento y exterminio, vividas durante el siglo XX con motivo de las guerras mundiales, los procesos acelerados de modernización y el terrorismo de estado vigente en las dictaduras del Conosur, han constituido el recuerdo como un objeto y fuente de conocimiento ordenado a recuperar las voces de sectores silenciados y a cuestionar la historia nacional tradicionalmente concebida desde los archivos, la cual se abre hacia una confrontación con la memoria. ${ }^{1}$ El estudio del pasado reciente se articula a través de una relación crítica entre memoria e historia dando paso a reflexiones que vinculan las posiciones teóricas epistemológicas con el poder político. Surgen, así, tematizaciones de reflexión relacionadas con la objetividad de la investigación histórica vs. la subjetividad de la memoria; el rol de la memoria colectiva en la constitución de las identidades colectivas; el desmontaje de discursos sobre el pasado que realiza la memoria; los presupuestos éticos implícitos en el trabajo investigativo sobre el pasado cercano y su relación con las experiencias de tortura y genocidio; y la relevancia y rol de la memoria frente a la historia. Tales disputas formarán parte del corpus de estudio del pasado reciente que sitúan este objeto investigativo en un contexto político contingente y en un campo discursivo, el de los usos del pasado.

Memoria e Historia constituyen dos modos de registro de la experiencia que permiten situar el pasado cercano como una referencia de reflexión entre las que se trenza una relación inevitable para la búsqueda de verdad. Las discusiones entre los diversos investigadores se ordenan, en relación con el estatus asignado a cada registro en su recorrido hacia el pasado. Mudrovic ha destacado los campos problemáticos que se originan en el estudio de la historia reciente. El primero dice relación con el estatuto epistemológico del recuerdo; su presentación como historia oral, manifiesta por alguien que narra y su consideración como fuente documental. Ésta se proyecta como función reconstructiva de los eventos del pasado, a la vez que como una capacidad interpretativa portadora de sentido. Se afirma que la memoria constituye un mecanismo de registro selectivo, rasgo que afectaría también al historiográfico en tanto todo recuerdo individual (así como todo documento) es recodificado en un tiempo público:

La memoria individual y colectiva se constituyen en mutuo diálogo. La memoria colectiva no consiste en la transmisión de un conjunto de hechos acerca del pasado, sino es ante todo, un código semántico que opera como contexto en el proceso de recuperar los recuerdos individuales. Los recuerdos, entonces, constituyen configuraciones de sentido de eventos seleccionados a partir de "lugares de la memoria" (...) Desde esta perspectiva queda descubierto el rol mediador del historiador entre el presente y el pasado reciente. Al hecho de que no hay modo definitivo, quirúrgico de separar lo fáctico de lo alegórico en los testimonios orales, se suma la cuestión de que los datos que el historiador recaba sólo cobran sentido dentro de patrones de ensamble y narrativas que son convencionales, políticas y significativas dentro de condiciones institucionales en que se desenvuelve la disciplina (Mudrovic, 2005:117).

Ver proyecto de Pierre Nora, en Francia, y los trabajos en Alemania y Estados Unidos. En América Latina, en medio del contexto de dictaduras, la Historia oral se articula como una apertura de participación de sectores silenciados por la historia oficial-autoritaria expresando un discurso contra hegemónico a través de la Historia Oral de los 80 . 
El recuerdo proveniente desde una entrevista o como retención de retenciones transmitida a través de diversas generaciones, adquiere el estatuto de documento significante en tanto lo rememorado se relaciona con el tiempo social estructurado en torno a los lugares o referentes simbólicos del pasado que se intenta reconstruir. Desde esta perspectiva, no es posible sostener una separación radical entre presente y pasado en tanto las memorias que constituyen fuente de conocimiento tienen la función de reconstituir permanentemente la experiencia vivida. Toda memoria asegura la continuidad del pasado en el presente. ${ }^{2}$ En este contexto, la relación entre memoria e historia se constituye desde una dimensión práctica que configura sentido a la experiencia temporal, ambas desarrollan una función orientadora y en relación directa con el grupo a quien está dirigida. El segundo punto de conflicto se refiere a la contemporaneidad del historiador ubicado en la inmediatez del tejido social histórico. La separación entre pasado y presente se vuelve más difusa y tanto el investigador como el recuerdo (objeto de investigación) son situados en un contexto mediado por "intereses prácticos" que contextualizan las significaciones en el marco de los discursos sobre el pasado reciente como una producción social del presente que exige, además, una definición de sus alcances ético-políticos. Cuando se estudia el pasado reciente, el rol del historiador no queda circunscrito al de un observador analítico dejando de lado su neutralidad moral cuando el evento abordado es un crimen contra la humanidad. Se enunciaría, así, la imposibilidad práctica de la historia como neutralidad ética. $^{3}$

La pretendida neutralidad valorativa de la causa por sobre la culpa se desdibuja cuando pesa sobre el fenómeno analizado del pasado reciente la categoría jurídica de crimen (...) la neutralidad valorativa que está en la base de la intencionalidad de la ciencia histórica debiera servir como plataforma crítica para la puesta en escena de los intereses y valores que operan como marcos de sentido de la generación a la que pertenece el historiador, y que funciona como locus socio histórico de autoatendimiento ético -político desde donde se reconstruye el fenómeno y no como garantía incuestionada de una presunta reconstrucción objetiva (Mudorvic, 2005:129).

Ricoeur, desde una filosofía narrativista de la historia, sostiene que la continuidad entre la configuración narrativa y la experiencia temporal respecto del pasado reciente abren la tensión entre el discurso histórico, la memoria colectiva y el contexto del historiador. El discurso histórico, el historiador, la operación historiográfica, la memoria colectiva, las políticas de la memoria y el uso político de la memoria forman parte de un mismo campo problemático. ${ }^{4}$ Desde estas perspectivas, el pasado reciente se ha abierto a cuestionamientos relacionados con el peso y valor del recuerdo estatatuido a través de la memoria y la historia. Encontramos quienes, marcando una diferencia aguda entre memoria e historia, proponen desarrollar una historización del pasado cercano (Aróstegui, 1997 y

2 Mudrovic introduce a Hobsbawm para afirmar: "Toda historia contemporánea es una forma de memoria aunque se reconozca en la historia una instancia de crítica del recuerdo" (2005: 118).

3 Ver dimensión pragmática de la memoria en Ricoeur (2004). El Pasado Reciente y las experiencias de holocausto exigen que éste sea recorrido desde un camino hermenéutico y una reflexión crítica de la historia efectual (Gadamer), en tanto su existencia nos constituye a partir de los efectos, por lo cual su estudio siempre debe ser enfrentado con vistas al presente heredado y su cuestionamiento. Ver también Mudrovic (2005: 119 y 122).

4 Ricoeur afirma que ninguno de los dos registros en disputa se excluyen mutuamente. La memoria es el sustrato y condición de posibilidad del pasado objetivado por la investigación histórica. 
Santos Julia, 2005). Desde este enfoque, la historia se vería presionada por la intención de imponer discursos historiográficos tanto desde las políticas de la memoria que aspiran a la cohesión social y por las memorias que la acusarían de falta de representatividad. El caso de la experiencia traumática vivida por la sociedad española en relación con su guerra civil ha presentado diversos discursos de memoria histórica, designados como memoria pública o colectiva para conceptualizar el proceso del franquismo (Aróstegui, 2006). Frente a éstos, Aróstegui considera una falacia sostener que la memoria histórica vendría a corregir las omisiones del discurso historiográfico dado que la memoria histórica sería en sí misma, también, historia. Cuestiona su pretensión de confrontar la validez del discurso histórico erudito, basándose en el supuesto de que éste no reflejaría del todo las memorias vivas .Y afirma que este afán correctivo y fiscalizador de la memoria descansa en una falacia dado que la memoria por sí misma no representaría el pasado, entre otras cosas porque no existe una tal memoria, sino unas varias memorias (Aróstegui, 2006: 56).

Aróstegui y Santos Juliá enfatizan que la llamada "memoria histórica" no es más que el resultado de las políticas públicas y privadas de la historia, una pedagogía de sentido que un determinado poder pretende dar al pasado para legitimar su acción en el presente. Son memorias afectadas por los cambios en "la cultura política" y los "proyectos colectivos políticos-sociales", productos ideológicos puestos en relación con el cambio generacional muy distinta de la memoria individual del testigo (cit. en Ruiz Torres, 2007). Desde una perspectiva contraria, Ruiz Torres ha destacado cómo desde la emergencia de la crítica desde la memoria hacia las políticas de olvido desarrolladas en la experiencia española, se ha producido una imbricación entre memoria y discurso político de la memoria. Según su visión, el trayecto Español se habría caracterizado por las elaboraciones de una "negación de memoria" (1936-1977), unas políticas de olvido (1977-1981) y, finalmente, la suspensión de memoria (1982-1996). ${ }^{5}$ Este propio devenir de las políticas del recuerdo sobre la guerra civil, puede ser considerado como objeto de aprendizaje público sobre las formas de abordar la experiencia traumática y los modos en que los acuerdos entre las élites políticas han dado respuesta a estos desafíos en la transición y consolidación de la democracia española. El aprendizaje social de la experiencia del trauma revela que éste se resolvió mediante una repartición de culpas; una generalización de la contienda y la culpa; una interpretación en clave de locura colectiva para llegar a la lección del nunca más. Este análisis cobra relevancia en relación a las políticas de la memoria desarrolladas en nuestro país, las que, fundadas en los Informes de Verdad y unas tesis históricas explicativas de carácter elitista, adolecen de una conceptualización de una ciudadanía moderna y responsable e introducen un aprendizaje social del perdón y la reconciliación fundado en categorías implicadas en un aprendizaje histórico de la desigualdad (cristianismo hispánico-colonial). Ruiz Torres reafirma la necesidad de uso del término memoria histórica, entendida ésta como los recuerdos de una experiencia directa del pasado, que a pesar del tiempo transcurrido, se habría mantenido vivos en los sucesivos presentes como crítica de la Historia. La designación "memoria histórica"

5 "La investigación ha construido el objeto de estudio "memoria histórica", "política de la memoria" y lo ha proyectado hacia atrás en el tiempo, en función de los intereses y preocupaciones actuales. Ha descubierto una problemática nueva, la de los discursos y políticas del pasado próximo y traumático con vistas a la acción del presente, políticas del estado o de ciertos grupos sociales, mitos y leyendas, culturas políticas, ideologías y mentalidades" (Ruiz Torres, 2007: 12). 
se utiliza como contrapunto a una falta de memoria relativa a esos hechos. Por lo tanto, detrás del concepto no habría continuidad sino ruptura de memoria. ${ }^{6}$ Así, la memoria colectiva y la memoria histórica como prácticas sociales remiten a los grupos que las elaboran, se apropian y la utilizan

(...) sin que en la primera haya nada de natural, por cuanto siempre están en juego las correspondientes y cambiantes relaciones de poder que existen en todos los grupos sociales. Las dos son por tanto, en ese sentido, memorias políticas. La memoria colectiva se modifica con el tiempo y adquiere la condición de histórica cuando hace referencia a acontecimientos de enorme impacto en la vida de un grupo social, ¿Cómo entonces hacer distinciones entre una y otra memoria? Ambas enfatizan los discursos públicos sobre el pasado y la construcción interesada del mismo, están lejos del recuerdo en sentido estricto o "verdadera memoria" (Ruiz Torres, 2007:19).

Desde esta perspectiva, la memoria individual y colectiva no se pueden separar drásticamente de los discursos y de sus usos sobre el pasado. El recuerdo, como fenómeno de la memoria, se constituye a partir de imágenes y huellas, por ello su narrativa no puede ser un reflejo exacto del pasado. Más bien éste recorrería un camino opuesto a la historia que investiga, actualizando el pasado y el presente del pasado, confrontando imaginación y rememoración. En esta dirección, se cuestiona la separación drástica entre memoria e historia y la teorización del fenómeno mnemónico sólo como una regularidad social, suponiendo que existen leyes generacionales exactas del recuerdo del pasado traumático que se modificarían cada 25 años. La reflexión del fenómeno del recuerdo más bien consideraría la distinción de registros que se articulan de manera compleja en la vida política para actualizar el pasado. ${ }^{7}$ La memoria es conocimiento inseparable de las emociones y de los juicios de valor, como cualquier otra forma de conocimiento, incluido el saber histórico y por ello es conocimiento orientado a intervenir el presente, para hacer frente a los problemas cotidianos de la existencia. Por eso resulta inseparable del uso práctico del pasado con fines diversos, de supervivencia, de identidad, de legitimación o cuestionamiento de un determinado orden establecido. La recurrencia al pasado reciente se explicaría según Ruiz Torres, por una resistencia de ese pasado a convertirse en pasado histórico, éste sigue vivo, mantenido así por los herederos de las víctimas, grupos de opinión y medios de comunicación. Un segundo factor es el interés creciente que ha alcanzado el estudio histórico sobre los discursos y las políticas de la memoria expresados en distintos contextos y culturas. Esto ha propiciado una "cultura

$6 \quad$ Es el carácter de ese pasado y su vínculo con el presente que explica la conceptualización de memoria por sobre la de historia. La designación de memoria para el pasado reciente en el caso español contiene, en sí, la valoración y reflexión del pasado traumático franquista y el valor político y cívico dado a las víctimas. Por ello, reivindicación de memoria no es lo mismo que conocimiento histórico del pasado. Los historiadores suelen contraponer la memoria colectiva e histórica a la historia, y por otra, diferenciar la primera de la memoria individual o verdadera memoria. Marie-Claire Lavabre propone además distinguir entre "memoria histórica", "memoria colectiva" y "memoria común". La "memoria histórica" no designaría lo vivido, ni la experiencia, ni los recuerdos, sino el proceso por el cual los conflictos y los intereses del presente operan sobre la historia y, de ese modo, identifica "memoria histórica" con "los usos del pasado y de la historia, tal como se la apropian grupos sociales, partidos, iglesias, naciones o Estados" (Ruiz Torres, 2007: 18-19).

7 Ruiz Torres, parafraseando a Ricoeur, considera el fenómeno mnemónico como representación en tanto el recuerdo aparece como "la imagen de lo que antes se vio, oyó, experimentó, aprendió, adquirió; y es en términos de representación como puede formularse el objetivo de la memoria en cuanto ella se dice del pasado" (Ibíd., 24-26). 
de la memoria europea contemporánea" del pasado reciente traumático. Aquella que ha aportado las nociones de memoria viva; el valor del testigo, el deber de la memoria, designaciones que remiten a la memoria del Holocausto. Se agregan perspectivas de un pensamiento anti fascista y una necesidad de evocar el pasado como fuente de revitalización de utopías de las que carece el presente (proveer de aquello que no logró brindar el futuro). Una apuesta democrática y de revitalización de la política en medio de una creciente fuerza de olvido y dispersión.

\section{EL PASADO RECIENTE EN LA EXPERIENCIA CHILENA}

Nuestra experiencia del pasado reciente dictatorial (1973-1990) no ha escapado a las discusiones, propias de los procesos de elaboración de la memoria histórica descritos. Estos han sido liderados por los gobiernos de la concertación, los que una vez recuperada la democracia fundaron su gobernabilidad en una estrategia que procuró alejarse del pasado y apostar al futuro modernizador como fuente de cohesión y sustentabilidad democrática. En este contexto político, la memoria histórica de nuestro pasado reciente, entendida como memoria compartida, se ha elaborado en el marco de una visión oligárquica de lo público fortalecida por el imperio del mercado como regulador excluyente de las relaciones sociales y los bloqueos epistémicos morales provenientes de las Ciencias Sociales y la historia, los que han evidenciado un déficit para estudiarlo e integrarlo como objeto de análisis. Y es precisamente la experiencia vivida por nuestra sociedad el quiebre de la convivencia republicana y la instalación de un política de CAMPO que promovió el exterminio, el encarcelamiento y la tortura sistemática, las que se abren como un pasado que cuestiona al presente.

La verdad pública ha sido establecida a través de los Informes de Verdad Rettig (1991) y Valech (2004), los cuales han definido los marcos históricos interpretativos y han orientado la elaboración pública de la memoria histórica. La discusión política ha constituido tres tesis históricas explicativas de la crisis de la convivencia republicana. La primera, la inevitabilidad de la violencia, supone que los hechos de violencia se desarrollaron al margen de las decisiones sociales e individuales. Vistos como una fuerza irreductible habrían ascendido en la escena pública hasta terminar con el estado republicano. La segunda, la crisis republicana, sustentada en una visión histórica conservadora que asume la experiencia política del siglo XX como un proceso de decadencia perpetua del estado nación decimonónico. Ambas se han construido a partir de una convergencia de principios del cristianismo hispano colonial y de nuestra experiencia republicana nacional de arraigo conservador. Y la tesis de la guerra fría, elaborada como una estrategia conciliadora (2003) por la clase política y las FFAA para mirar en perspectiva el golpe de estado a treinta años y fundar un nuevo pacto político sustentado en la ausencia de culpas de la clase política, en tanto el contexto mundial explicaría la violencia vivida. ${ }^{8}$

8 La tesis de la guerra fría, vigente desde el 2003 hasta hoy, viene a contener discursivamente estas prescripciones normativas y a dar una "explicación histórica" -la guerra en un contexto mundial-, permitiendo la convivencia de estas narrativas en un presente estable que se reproduce como discurso social sobre el pasado. La tesis fue presentada por Lagos en el 2003 con motivo de los 30 años del golpe militar, recuperada por el "Nunca más" del General Juan Emilio Cheyre y vinculada, finalmente, al dolor social proveniente de los testimonios de quienes fueron torturados y apresados en la dictadura presente en el Informe Valech en el 2004. 
Caracteriza la instalación de estas tesis la ausencia de una discusión pública y de participación ciudadana. ${ }^{9}$ El pasado reciente ha quedado cerrado por las tesis expuestas, las que crean un imaginario de clausura, de etapa definitiva de una forma de convivencia política imposible de ser abordada como experiencia de reflexión.

Articulan el discurso sobre el pasado reciente las categorías del perdón vista como extensión social (a todos sin distinción) de las culpas, como imposición, y la reconciliación en tanto gesto de unidad y cierre de la experiencia traumática de violación de derechos humanos. Ambas presentes en el Informe Rettig, fundan sus significados en un pensamiento cristiano conservador de reminiscencias coloniales que admite en la multiplicación de las culpas hacia toda la sociedad la integración en torno al pasado. El Informe Rettig, centrando su relato histórico en el contexto anterior al golpe (1965-1973) y la dictadura, desplaza la atención hacia la causalidad de la violencia más que a su análisis, liberando, de paso, a los involucrados. Se agrega los rasgos metafísicos de su narrativa, la defensa de una verdad innombrada que debe ser aceptada como mandato superior y las consideraciones asociadas a un cristianismo hispánico (la conversión de ciudadanos a creaturas y la defensa del martirologio entre otros) como formas retóricas para justificar el dolor. La expresión de la memoria en el espacio público es así bloqueada coyunturalmente por el olvido forzado de la amnistía, la amenaza de Pinochet en la comandancia en jefe del ejército, la búsqueda de la estabilidad del sistema democrático, el miedo instalado por las políticas de CAMPO vividas y, sobre todo, por la ausencia de voz y cuerpo de las víctimas que pretenden ser restituidas en su dignidad en el Informe. En suma, por la imposibilidad de que los detenidos desaparecidos y los muertos recuerden.

El Informe Valech (2004) introduce el testimonio desde la huella del cuerpo sobre lo que fue el pasado dictatorial, al significar la tortura y la prisión ilegítima. Centra su relato histórico en la experiencia de la violación de DDHH en la dictadura (1973-1990) y valida como fuente de verdad, ya no una entidad metafísica sino el testimonio de una experiencia social compartida por las víctimas que están vivas; releva con ello a la ciudadanía y su memoria de dolor como fuente de verdad pública. Redimensiona el recuerdo y la ciudadanía, propiciando una responsabilidad moral de la sociedad ante la memoria del dolor, del quiebre del cuerpo personal y político. Sin embargo, no modifica el relato histórico del pasado reciente como res gestae, en donde el recuerdo se transforme en un objeto de reflexión ético político. Nuevamente, los hechos del pasado reciente dados en

9 La discusión pública se ha abierto en distintos contextos; hacia el 2004, asistimos a una elaboración del recuerdo del dolor y de la política de CAMPO evidenciados por el testimonio en el Informe Valech (se refiere a la Comisión de verdad contra la Prisión y la Tortura ilegitimas convocada por el Presidente Ricardo Lagos, presidida por el sacerdote Raúl Valech. La comisión tuvo como misión recoger los testimonios de las víctimas de violación de derechos humanos en el período 1973-1990, validando su testimonio como argumento para la política de reparación), el que ha sido cautelado políticamente a través de la Tesis de la guerra fría que vendría a evitar el desborde de la experiencia de dolor en el presente, consolidando un acuerdo para dar "estabilidad" al sistema político. Para el año 2010 se ha convocado a una reapertura del Informe Valech, proceso que sin duda abrirá una nueva disputa entre memoria, política e historia. Por su parte, el Museo de la memoria y de los derechos humanos, recientemente abierto, ha propiciado el contacto con un espacio testimonial público altamente valorado, pero no presenta una nueva tesis explicita sobre la experiencia vivida. El museo de la Memoria y de los Derechos humanos contiene un recorrido testimonial del período de represión dictatorial 1973-1990 vivido por nuestro país junto con muestras itinerantes referidas a la promoción del respeto a los derechos humanos y las políticas de reparación desarrolladas en distintos países. 
este caso, las condiciones de guerra fría, devinieron fuerzas inmanejables. ${ }^{10}$ Se produce el cierre del pasado desde preceptos religiosos. Mientras, el presente se abre desde el neoliberalismo, que procura distanciarse del pasado, y cuando éste es sindicado como causante de las desigualdades actuales, por su pecado de origen (cuestionar la base moral de la clase política conservadora adherente y colaboradora de la dictadura), se responde a este campo problemático apelando a la necesidad de progreso ilimitado y la libertad individual como realidades naturales y como conquistas políticas libertarias pseudo homologadas a los derechos humanos. Cuando esto no es posible por el carácter de la confrontación, se recurre a la culpa y reproducción del castigo de las víctimas. ${ }^{11}$ Coexisten con estos marcos narrativos de la historia del pasado reciente, memorias sueltas y emblemáticas que emergen en los diversos contextos en que el pasado es discutido. Nuestro pasado reciente no es conceptualizado como una experiencia histórica y se constituye a partir de principios ideológicos que actúan como prescripción y clausura de los eventos vividos. Nace, entonces, una memoria normativa de carácter moral, que impone la condescendencia y el silencio de eventos, contextos y nombres para significar lo indecible.

Al prevalecer una visión estructurante de la historia reciente (1970-1990), caracterizada por la naturalización de la violencia (Lechner, 2006), ésta es entendida como una fuerza imposible de contener que nos habría conducido a una guerra civil. Se la sitúa, además, dentro de un marco explicativo más amplio, en tanto formaría parte de un proceso histórico decadentista que caracterizaría la finalización del siglo XX. La fuerza de la violencia vendría a ratificar el trastrocamiento de la nación imaginada, aquella entendida como un ente metafísico superior, protector y regulador del orden social (Tonalidad de la discusión pública que genera el Informe Rettig). Desde este marco, es posible representar la crisis política de 1973 como expresión y aceleración de esa decadencia a la vez que causa del golpe de Estado. En esta visión, el mundo social se presenta subordinado e invisibilizado ante la exaltación del estado nación. ${ }^{12}$ La naturalización del curso de la historia se vuelve a recomponer en el 2003-2004, pero como argumento conciliador de la sociedad reconstruida. El propio Presidente Lagos lo incorporaría como fundamento de restitución de la ciudadanía y de la república, liberando del juicio público a la clase política y los representantes de instituciones involucradas en violaciones de DDHH, en tanto sus actos se explicarían por las fuerzas movilizadoras de los procesos de guerra fría vividos desde mediados del siglo XX. ${ }^{13}$ Asiste a estas construcciones del pasado

10 La tesis de la guerra fría junto con otros rituales impulsados por Ricardo Lagos, procuraría extender un halo de integración y de representación purificada de la sociedad. En su gobierno se produce el "Blanqueo de la Moneda", la casa de gobierno es pintada de blanco, dando otra mirada a la construcción gris bombardeada en 1973. El propio presidente reabre simbólicamente la entrada por la puerta de Morandé 80(2003), clausurada por la dictadura, realizando una reconversión de los símbolos republicanos asociados al liderazgo de Allende. Opera una especie de restitución. Para algunos, el "blanqueo de la moneda" es una limpieza de imagen que propende al olvido no consensuado (Silva, 2006). Para análisis de las categorías del perdón y reconciliación en Rettig y las bases de una ciudadanía moderna en el Informe Valech, ver Rubio (2010).

11 Ver discurso de Andrés Allamand (2005)

12 La visión conservadora de la historia ve las transformaciones sociales y políticas del siglo XX como una progresiva decadencia del Estado y una corrosión de las bases morales de la nación. Quienes apoyaron la dictadura de Pinochet la consideraron como la salvación restitutiva y a la vez refundacional de la nación convertida nuevamente en Patria. Para comunidad imaginada, ver Bengoa (1996).

13 El Informe Valech incorpora este argumento que es compensado con el testimonio vital de quienes sufrieron los apremios ilegítimos de la dictadura e integra el testimonio que llama a responsabilizar a toda la sociedad. Esto genera dos efectos: la invisibilización y la desresponsabilización de la clase política, así como la cercanía 
una memoria banal que absolutiza la consideración de los hechos, al verlos como un conjunto de eventos inmovilizados e inmodificables. La ausencia de memoria histórica compartida da cuenta de la subjetividad social, que no ha podido construir una expresión temporalizada de sí misma, evidenciando un colectivo débil (Lechner, 1998). Las nuevas democracias post dictatoriales habrían fracasado en construir una reconciliación, en tanto las estrategias desplegadas no han eliminado el desacuerdo con el pasado. Más bien, éstas habrían ordenado su hacer en torno a la estabilización política “(...) teniendo como base un acuerdo con los ex-gobernantes; la invención de una forma de justicia, que sea paliativo de la justicia penal; la restauración de la "dignidad" de las víctimas, y el establecimiento de un relato histórico razonablemente consensual, pero que tiene que ser dialogado" (Lefranc, 2003; en línea). Se considera que las estrategias utilizadas han sido eficaces si los mecanismos de justicia desplegados permiten la construcción de un relato razonablemente consensual que promueva el pluralismo de las visiones y el diálogo acerca de la historia capaz de cristalizar en un relato que albergara en sí mismo el disenso. Un mecanismo es eficaz si contribuye a la elaboración de un acuerdo democrático, o sea de un acuerdo sobre las normas de expresión del desacuerdo. Según Lefranc, los mecanismos de justicia desplegados no habrían bastado para articular la reconciliación dado el carácter de nuestra democracia reconstruida, que como democracia representativa, no habría incluido a la minoría, es decir a las víctimas y allegados en la gestión institucional e histórica del pasado reciente (Agamben, 2004).

Por su parte, el discurso historiográfico se enmarca en prescripciones que consolidan la clausura del análisis al argumentar que el pasado reciente es un objeto complejo y es oportuno esperar el futuro para abordarlo con "objetividad y distancia". Hasta ahora, el pasado reciente como experiencia histórica se ha recuperado desde una discusión en torno a la verdad y el trauma. ${ }^{14}$ El modo en que se ha elaborado la verdad (como imposición absoluta totalizante y excluyente para caracterizar la experiencia) ha dado origen a un campo problemático. La verdad ha sido usada como criterio normativo y, a la vez, como categoría para definir el contenido del pasado por defensores (de la salvación de la patria) y opositores a la dictadura (víctimas de la tortura e injusticia como mentiras y prácticas institucionalizadas), así como por la propia Concertación (para la justicia, reparación y reconciliación para la democratización). Frente a este campo problemático, algunos historiadores aspiran a subordinar dichas apreciaciones al discurso historiográfico. Considerando los documentos como fuente de rigor histórico, ${ }^{15}$ cuestionan el carácter y la intención política de reconciliación asumida por los Informes de Verdad en tanto instrumentalizarían la verdad al otorgarle el poder de reconciliar y de reestablecer sociabilidades quebrantadas. Al procurar “(...) generar una verdad canónica se acallan las interpretaciones del pasado que están en conflicto” (Palieraki, y Torrejón, 2008: 33).

Procurando diferenciar de manera absoluta la historia de la memoria y del texto político sobre el pasado reciente, se cuestionan también los testimonios usados por las Comisiones (como fuente de judicialización y de verdad histórica), corriendo el riesgo de

de la sociedad con quienes sufrieron.

14 No integramos en este análisis las recuperaciones de crónicas y novelas.

15 La mayor parte de los historiadores en nuestro país cuando aborda el pasado reciente no se considera a sí mismo como parte de esa memoria, sino que se auto confiere un poder y saber amparado en la disciplina. No cuestionamos la trascendencia de la disciplina sino la ausencia de crítica del investigador en particular, la ausencia de una confrontación desde los efectos de ese pasado. 
una "fetichización" de su facultad de reconstrucción histórica. Los Informes de Verdad tenderían a crear un escenario de víctima y victimario, reduciendo el relato de manera simplista. Se considera, además, que los historiadores del pasado reciente en curso se han transformado finalmente en historiadores de la memoria, promoviendo una confusión ideológica de los registros sobre este pasado. ${ }^{16}$ Cuestionando El Manifiesto de Historiadores sobre la verdad histórica se afirma:

Quisiéramos subrayar la confusión de registros, político e historiográfico dentro del texto y atrevernos a señalar algunos de los peligros que esta confusión acarrea. Por un lado se contesta a la carta de Pinochet o a las declaraciones de los políticos de la Concertación como si se tratase de una interpretación histórica consistente, cuando en realidad se trata de una justificación ideológica de actos políticos. Al mismo tiempo, la función que se le atribuye a la historia es fundamentalmente política: - "La historia será el medio de ejercicio de la soberanía popular y de defensa de los DDHH". Pero esta apreciación lleva aparejada la creencia de una sola verdad histórica que sería la popular (...) No podemos sino constatar aquí, la permeabilidad del debate historiográfico al debate político. Esto se debe claramente a la proximidad temporal y la intensidad traumática que tuvo el golpe militar y la dictadura en la sociedad chilena" (Palieraki y Torrejón, 2008: 39).

El llamado deber de memoria pondría el trabajo historiográfico a expensas de la identificación ideológica del historiador con algunos sectores silenciados, corriendo el riesgo de no someter los relatos a una crítica y transformarlos en una verdad canónica. ${ }^{17}$ Palieraki y Torrejón afirman que la consigna el deber de la memoria, con la memoria como objeto de la historia, puede ser sólo comprensible en un contexto donde la historia se hizo primero desde la política, donde el objetivo no es establecer una interpretación crítica que cumpla criterios de validez, sino participar en un debate que se está desarrollando en el espacio público. Pero eso no podría dar pie a confundir el trabajo crítico de la disciplina: "La historiografía no puede hacer la memoria de los pueblos, debe hacer la historia de los pueblos. Nos parece necesario pasar del uso político del pasado a su uso público" (Palieraki, y Torrejón, 2008: 43). Esta crítica omite que, cuando se trata del pasado reciente, los registros de memoria, historia de vida, memoria colectiva (mediada por la historia oral y el testimonio), la historiografía, las políticas de la memoria y los usos políticos del pasado, se encuentran asociados en un entramado de discursos que enuncian diversas tonalidades narrativas, algunas más parcializadas que otras, pero todas vinculadas entre sí y afectadas por el recuerdo. No existe un registro privilegiado por sí mismo. Se evidencia la precariedad que alcanza el marco historicista para dar cuenta de estas discusiones y posicionamientos teóricos cuando se trata del pasado reciente. El carácter de los acontecimientos experimentados demanda integrar nuevas perspectivas que dimensionen lo vivido y sus efectos. Las perspectivas hermenéuticas críticas que

16 Al usar preferentemente la fuente oral y crear un texto que se compromete con el deber de la memoria y da paso a un ensayo de interpretación histórica. Se incluyen en el caso chileno, los historiadores de izquierda los que estarían "involucrados ideológicamente". Palieraki y Torrejón (2008: 39) aducen que, en el caso Francés, los temas de la resistencia y la colaboración fueron tratados por el medio académico con un mayor distanciamiento.

17 El contacto de muchos de estos historiadores con la historia oral anglosajona y su cercanía con los movimientos de DDHH y las víctimas, les dotarían de argumentos para la ruptura epistemológica de la historia oral, que actuaría como reverso y contrapunto de la historia oficial dictatorial orientando el deber de memoria hacia los excluidos y perseguidos. Ver Garcés y Leiva (2005). 
consideran los posicionamientos del investigador, que actúa desde los efectos de dicho pasado y responsabilizándose, presentan orientaciones definidas para su estudio y reflexión Osorio y Rubio (2006). Hablar del pasado reciente considerando la memoria como categoría reflexiva exige transparentar la posición ética política en la cual se funda el relato emergente y no invisibilizarse detrás del análisis documental o del acontecimiento. Contrariamente al llamado a hacer la historia de los pueblos en lugar de la memoria de los pueblos como una interpelación disciplinaria, (para asegurar la atención del investigador sólo al pasado-el reciente o el lejano-) es precisamente, porque no se confunden los registros disponibles, que se destaca la variedad que éstos pueden alcanzar y los puntos de conexión que es posible establecer cada vez que se recuerdan las experiencias compartidas. ${ }^{18}$ Desde el reconocimiento de la selectividad de las experiencias y hechos rememorados, quien investiga sobre el pasado reciente desde esta perspectiva puede abrir a procesos de reflexividad. El pasado reciente puede ser concebido como un campo de discusión abierto en el cual están presentes los posicionamientos políticos del presente y los deseos de futuro. Es en esa inflexión, precisamente, en que es oportuno definir el fundamento político que alcanza el recuerdo y su elaboración.

\section{EL PASADO RECIENTE EN EL CURRÍCULUM ESCOLAR}

La formación ciudadana ha sido una preocupación permanente de los gobiernos de la concertación, no obstante, las perspectivas y las densidades involucradas han evidenciado una débil cristalización en su relación con el pasado reciente. Participan de dicho proceso (1990-2006) las discusiones políticas motivadas por los hallazgos de cuerpos, los Informes de Verdad, los procesos judiciales contra los violadores de DDHH y la detención de Pinochet en Londres, que obligaron a reconocer públicamente la represión dictatorial, la muerte y la desaparición. ${ }^{19}$ Tales hechos se consolidan como memorias hegemónicas que orientan una pedagogía de sentido de la experiencia social; las tesis explicativas ya descritas sirven como contenedoras de una memoria caritativa y doliente, fundada en la prescripción del perdón que abre paso a una memoria indolente que cuestiona la existencia histórica de la práctica de la tortura, la desaparición, muerte y prisión como expresiones reales de la política de CAMPO. ${ }^{20}$

Es posible reconocer tres momentos en este diálogo educativo con el pasado reciente; el período 1990-1996, en que se realiza una modificación de programas de formación ciudadana y de enseñanza de la historia, hecho que también está afectado por los cambios en los sentidos de la reforma educativa. Se trata de un período en que la orientación de modernización se sustenta en un fundamento comunitario-social. El segundo, entre

18 Ver las implicaciones éticas y políticas del texto y de su relación con la acción en la perspectiva crítica de Ricoeur.

19 Incluyendo en gran parte la presencia activa en la política y el ejército de Pinochet 1990-1998, un hecho visible fue el reconocimiento en el 2002 de las FFAA como responsables de haber tirado cuerpos al mar -lo que permitiría explicar de otro modo el silencio ante el acontecimiento de desaparición de los cuerpos y de la figura jurídica política del "detenido desaparecido".

20 Wilde (1999, cit. en Anne Pérotin-Dumon, Dir., 2007), señala la necesidad de examinar con mayor detalle las transiciones pactadas. En el caso de Chile, además de las limitaciones institucionales y los costos fundacionales de la construcción inicial, se agregan los costos relativos a la legitimidad y la identidad de nuestra sociedad. 
1996-2006, en que la modernización gira hacia los principios de la calidad y la equidad y se ordena desde el tecnicismo y el rendimiento sin modificar el tratamiento del pasado reciente, diagnosticando problemas en la formación ciudadana (Comisión 2004), sin realizar una discusión pedagógica sobre el sentido de los procesos formativos; y el período 2006-2010, en el cual se desarrollan ajustes curriculares aun en marcha y el pasado reciente es valorado como espacio para fortalecer una formación ciudadana en crisis, en aras a consolidar la democracia construida desde los 90.

El foco de atención de estos procesos ha estado en los jóvenes, dada la apatía política, la baja inscripción en los registros electorales, la delincuencia, la violencia en los entornos públicos y el aumento del consumo de alcohol y drogas considerados como síntomas de una falta de integración, un fenómeno transversal, aunque agravado en los sectores populares, hechos que hasta hoy persisten. La política de crecimiento con equidad sustentada por la alianza de gobierno consideró que el éxito del plan dependía de la eficiencia del sistema escolar en su preparación valórica y técnica de las nuevas generaciones. ${ }^{21}$ Así, el antiguo currículo de Historia y Geografía experimentaría tres cambios: el currículo centralizado sería reemplazado por un Marco Curricular de Historia y Ciencias Sociales basado en la formulación de contenidos mínimos Obligatorios (CMO) y objetivos Fundamentales Transversales (OFT), a fin de que en el futuro los propios establecimientos elaboraran sus programas de acuerdo a su tradición local o comunitaria. ${ }^{22}$ Los contenidos de la Enseñanza Media se estructurarían desde un marco constructivista, para integrar el contexto juvenil en el relato histórico. Así, la enseñanza histórica partiría desde la comunidad local, para luego ser integrada a la comunidad nacional, regional y finalmente internacional. Finalmente, los contenidos referidos a la historia reciente de nuestro país se ordenarían en una gran macro unidad, Historia de Chile, concentrada en segundo año de Enseñanza Media, siendo vistos sólo tangencialmente en sexto grado. El pasado reciente requería ser incluido desde un marco explicativo que dejara paso a la construcción del consenso con los jóvenes pero que recogiera las prescripciones éticas y políticas establecidas por la Concertación. El marco interpretativo del pasado estuvo definido, en un primer momento, por la tesis de la inevitabilidad de la violencia, la crisis republicana y las categorías del perdón y la reconciliación. La narración del quiebre republicano y de la instalación de la dictadura y sus políticas represivas debió enfrentar episodios críticos $(1992,1996)$, que supusieron su ajuste. Hacia 1998, con la prisión de Pinochet en Londres, su "Carta" al país ratificó los hitos y consideraciones ya pactadas sobre el pasado reciente, la inevitabilidad del golpe de Estado, el éxito del modelo económico y la necesidad de la reconciliación nacional. ${ }^{23}$ En respuesta, el Manifiesto de Historiadores (1998) se propuso combatir las "verdades históricas" acuñadas por el Pinochetismo. Entre las falacias y omisiones, destacó:

21 El comité técnico asesor del diálogo Nacional sobre la Modernización de la Educación Chilena convocado en el gobierno de Eduardo Frei en 1994, redactaría el documento "Los desafíos de la Educación Chilena frente al siglo XXI". Ver Reyes (2008: 69).

22 El tiempo evidenciaría la inviabilidad práctica de esta propuesta dadas la escasa disponibilidad de tiempo asignado por el ministerio para integrar contenidos propios y la falta de capacidad de la mayoría de los establecimientos para elaborar sus propios programas.

23 La carta fue redactada por sectores de la UDI en el contexto de la prisión de Pinochet (1999). Ver http://www. fundacionpinochet.cl/historia/doc_los_gestos.html 
1. Reducir el proceso histórico al período en que es posible justificar el golpe; 2. El silenciamiento de los procesos históricos estructurales y de la correspondiente responsabilidad oligárquica acumulada; 3. La atribución de la crisis de la política de 1973 a la implementación de las reformas económicas y sociales; 4. La ineludible y moralista intervención armada de los militares; 5. El acallamiento de los excesos faccionales cometidos por el gobierno militar y después de 1973 (cit. en Reyes, 2005: 75).

El marco curricular vigente para el pasado $^{24}$ reciente tendió a centrarse en la polarización social reinante vista como causalidad del golpe de estado de 1973; evitar responsabilizar a las FFAA del golpe; silenciar las dimensiones explicativas que aporta el tiempo largo y el análisis del orden estructural; y tender a obviar la designación de dictadura al gobierno militar, así como sustituir la noción de golpe de Estado por la de "irrupción de los militares en el poder" (Reyes, 2004). El pasado reciente inscrito en los textos de estudio fue explicado desde el contexto previo al golpe, entendiendo de manera restringida la experiencia, como una crisis de la república impulsada por la UP que habría propiciado el clima de violencia:

(...) a fines de 1972 y a comienzos de 1973, en las calles de las principales ciudades de Chile se produjo casi a diario violentas manifestaciones tanto a favor como en contra del gobierno. Los dirigentes políticos demostraban su incapacidad de lograr entendimientos para resolver el grave conflicto que afectaba a toda la sociedad (...) Hacia 1973 el país vivía una profunda crisis política, social y económica...el 11 de septiembre de 1973, las tres ramas de las FFAA, a las que se sumó Carabineros, exigieron por la fuerza el abandono del poder al mandatario elegido democráticamente: Este camino de revolución extremo significó el derrocamiento de Salvador Allende, quien se suicidó en el Palacio de la Moneda luego de que éste fuera bombardeado por la Fuerza Aérea. Con la intervención militar se produjo un quiebre profundo en la vida democrática que por largas décadas había tenido lugar en Chile (cit. en Reyes, 2005: 75).

De esta manera, se enfatiza la crisis social política como causante del fin de la convivencia republicana, se omite el concepto de golpe de Estado y se transfiere la responsabilidad general a la clase política representada en la figura de Allende (muerto). Dicho proceso comenzaría a ser desmantelado en el 2003 en el contexto de la conmemoración de los 30 años del golpe militar, cuando la figura política de Allende es recuperada por la opinión pública y respaldada por los rituales de Ricardo Lagos.

La mañana del 11 de septiembre de 1973 debe ser el momento histórico más dramático y decisivo de la historia de Chile del siglo XX. Sus consecuencias más allá de las simpatías y rechazos que generen, son indesmentibles. Tras el bombardeo al a moneda, el suicidio del presidente Salvador Allende y la instalación en el poder de una junta militar encabezada por el Comandante en Jefe del Ejército Augusto Pinochet Ugarte, el país no volvería a ser el mismo. El fin del Estado de bienestar y el cambio del modelo económico; la nueva institucionalidad política materializada en la constitución de 1980; y la sistemática violación de los Derechos Humanos, modificaron significativamente la faz de la sociedad chilena (Donoso et al., 2003: 312).

El programa sugiere que la unidad pasado reciente se vincule directamente con la valoración de la democracia, la aceptación del pluralismo político y cultural y el respeto

24 El Marco Curricular para la enseñanza básica en 1996 y para la secundaria en 1998, modificado en junio de 1999 (decreto 40 se refiere a horas y orden de contenidos). 
de los derechos humanos. Interesa que los estudiantes analicen la magnitud de los cambios económicos y políticos implementados por el régimen militar y la existencia de un modelo económico diametralmente opuesto a la sustitución de importaciones. Se enfatiza que:

Dada la cercanía temporal de estos procesos, y el drama humano implicado, es especialmente importante la conducción de los docentes; resulta clave que los jóvenes conozcan lo ocurrido de un modo amplio; identificando las distintas visiones en juego, a la vez que puedan reflexionar sobre ello, en un marco de valoración de la democracia y de respeto a los derechos humanos (Marco curricular, 1998: 69-70).

Se refuerza el concepto de crisis de la república (visión decadentista de la historia) y se enfatiza la necesidad de "aprender" sobre los cambios económicos e institucionales impulsados por la dictadura como un modo de dotar al presente de continuidad hacia el pasado reciente. Respecto de la experiencia del dolor, aduce que su cercanía temporal (ambigüedad) puede generar perturbación, dado el drama humano implicado. En ese marco, se responsabiliza al docente de la transmisión de una de las memorias sociales más complejas del pasado reciente, la de la política de CAMPO. El Estado, que ha promovido el perdón y la reconciliación como un mandato, luego se desliga de su responsabilidad de reflexionar sobre la experiencia, hecho que es transferido al docente, un ciudadano más que vivió estos hechos desde su memoria particular. El currículo promueve una política de la memoria ambigua; por un lado, propone el perdón y la reconciliación pero, por otra parte, no es capaz de transmitir una memoria responsable que integre los DDHH como un principio de comprensión de la experiencia social del pasado reciente, que evidencie las acciones de violación de derechos como hechos reconocidos y abordables.

Los ajustes curriculares en marcha (2009-2010), pretenden responder a demandas técnicas, así como al déficit de formación ciudadana existente. ${ }^{25}$ Se propone entregar herramientas para enfrentar los desafíos de un mundo que cambia aceleradamente y que es cada vez más complejo e interconectado. Se reafirma que la mejor manera de contrarrestar el riesgo de una enseñanza sesgada de la historia y de las ciencias sociales es abordar los temas revisando distintas fuentes e interpretaciones y fomentando el valor de las evidencias. En lo que respecta al pasado reciente, no se observan grandes modificaciones. Los contenidos se ordenan a partir de la tesis de la guerra fría como marco explicativo de la crisis y las unidades temáticas procuran enfatizar un camino lineal de logro, abriéndose a hitos políticos y económicos del pasado cercano que consolidan la democracia vigente. ${ }^{26} \mathrm{El}$ régimen militar, con sus subapartados, sigue casi inalterable en relación a la propuesta de 1999, no obstante, introducir decididamente las designaciones

25 Justifican el ajuste la extensión de la escolaridad obligatoria a 12 años, que obliga a mirar la forma en que se organizan los aprendizajes en el sector; los avances en el desarrollo curricular; la elaboración de Mapas de Progreso del Aprendizaje, que describen la secuencia del aprendizaje -desde lo más simple a lo más complejo- en un determinado dominio o eje curricular (MINEDUC, 2008; ver concretamente las indicaciones del informe de la "Comisión nacional de Formación Ciudadana" en línea, http://www.mineduc.cl/biblio/ documento/200510031858480.formacion.pdf, el Ajuste Curricular: Sector Historia, Geografía y Ciencias Sociales Jornadas Regionales Diciembre de 2008, en línea: http://www.currículum-mineduc.cl/ayuda/docs/ ajuste-curricular-2/Presentacion_Ajuste_Hia_Geografia_y_CSociales_100309.ppt).

26 Composición del pasado reciente en 3 subunidades: "Las transformaciones estructurales en Chile: Reconocimiento que luego de la Segunda Guerra Mundial la historia de Chile y América Latina se inserta en una época marcada por la Guerra Fría. El régimen militar y El proceso de recuperación de la democracia" (Ver Reportaje publicado el domingo 23 de octubre 2007 en www.saladehistoria.com). 
golpe y dictadura militar, así como la valoración de la lucha por los DDHH y la recuperación de la democracia, se exponen detalladamente, enfatizando decididamente las políticas públicas trazadas por los gobiernos de la Concertación desde 1990 en adelante, a saber, la "democratización” y el "Nunca Más" del Ejército (2003). El currículo se sigue ajustando a intereses del presente, en particular los de la concertación, que procura establecer una continuidad histórica de su obra, relevando como puntos centrales la estructura económica, la lucha por los derechos humanos y las políticas de crecimiento y equidad. Dichos ítems vistos como prescripciones y no experiencias históricas ordenan el pasado, no pretenden reflexionar sobre las tesis de la historia del período y no consideran las memorias emergentes. Se observa un posicionamiento político congruente con la democracia representativa, ${ }^{27}$ ante el cual el marco del continuum temático historicista (Benjamin) consolida el presente. El gran vacío es el docente, quien debe presentarse ética y políticamente ante sus estudiantes en un ámbito en que la experiencia es compartida, en donde no existe una voz única para hablar de ese pasado, y en que el presente actúa como referente de crítica para ambos.

\section{BASES PARA UNA PEDAGOGÍA DE LA MEMORIA}

Si abordamos el pasado reciente desde la memoria como categoría reflexiva, el recuerdo como objeto investigativo se enmarca en un contexto político contingente y en el campo discursivo de los usos del pasado, en el cual sus elaboraciones involucran apreciaciones políticas sobre el pasado y el futuro deseado. El modo de recordar el pasado reciente lleva implícita una evaluación de la sociedad en clave temporal. Cuando se discute sobre el pasado reciente, es el presente y su continuidad lo que está siendo enjuiciado. ${ }^{28}$ Nuestro pasado ha sido gestionado de acuerdo a intereses políticos que han prescrito su clausura y bloqueado su reflexión y crítica como experiencia vivida. La ausencia de memoria debilita nuestra propia la visión temporalizada, nos recluye a mundos interiores fragmentados y consolida una proyección de ciudadanía débil. Se requiere de una pedagogía para la enseñanza del pasado reciente que considere la memoria como categoría reflexiva, que confronte desde una crítica ético política el marco positivista que ha dominado su reconstrucción así como el determinismo de la causalidad naturalizada que se ha instalado como explicación de los eventos vividos. Esta propuesta atiende a la necesidad de fortalecer la ciudadanía debilitada sin un pasado y un presente que compartir. Considerando la ciudadanía como cristalización de memoria (Garretón, 2003) podemos observar que en nuestra sociedad se conjugarían de un modo ambiguo: modernidad, democracia, mercado y referencias públicas de corte oligárquico. Es de relevancia preguntarse en qué medida se ha construido una cultura política democrática capaz de responder a los problemas de nuestras sociedades y a pensar la vivencia de la política y de lo público colectivamente: “(...) vivimos hasta hoy y de modo cada vez más dramático, el tiempo como una secuencia de acontecimientos, de coyunturas que

\footnotetext{
27 El tratamiento de los DDHH desde un carácter normativo presente en el Marco Curricular (1999) no implica necesariamente un posicionamiento ético. Entendemos por posicionamiento la definición de ciertos principios orientadores y de su confrontación con la experiencia vivida.

28 Ver perspectiva hermenéutica crítica en Ricoeur (2004) y Calveiro (2008).
} 
no acaban de cristalizar en una "duración” (...) vivimos un presente continuo" (Lechner, N. 2008: 419).

En medio del bloqueo del pasado reciente y la indisponibilidad del tiempo social, se requiere pensar la ciudadanía en su historicidad, como una competencia histórica, como un aprendizaje y una "cualidad de experiencia social" 29 que debe abrirse a las dimensiones culturales históricas y éticas que la constituyen. Una reserva de memoria que se debe poner en movimiento para recuperar sus experiencias y reflexionar sobre sus posibilidades de expresión. El pasado reciente, es un marco temporal para pensar la enseñabilidad de la experiencia social de la ciudadanía. Su consistencia histórica se sustenta en el peso que adquirieron; la fractura de los aprendizajes históricos de la convivencia; la justificación discursiva de la eliminación del otro; la implantación de una ruptura indefinida del tiempo colectivo; la aplicación calculada de la violencia; la destrucción simbólica y real del cuerpo del otro enemigo; la instalación de la incertidumbre y el miedo permanente. Se requiere la construcción de una pedagogía de la memoria que contribuya a la formación ciudadana, que abra su dimensión temporal en perspectiva vital (constitución de subjetividades) y que vincule dicha condición a una existencia política con sentido. La pedagogía que asuma dicha tarea debe orientar su enseñabilidad vislumbrando un futuro político que se construya desde un horizonte que integre la historicidad de los hechos, la experiencia del pasado reciente, y la responsabilidad desde una visión de comunidad sustentada por una ética abierta al otro. En este marco, el recuerdo es reconsiderado como acción político pedagógica para la formación ciudadana que abre futuro compartido. Es pertinente proponer para una pedagogía ciudadana, la legitimación del recuerdo de la experiencia del pasado reciente como un horizonte estratégico pedagógico sustentado en:

- La necesidad de abrir la sensibilidad y la reflexión sobre el dolor, el daño y la pérdida en nuestra vida social. Propiciar una comprensión más profunda de la vida política y una formación moral de los sujetos que contribuya a una reflexión sobre el sentido de la acción en los tiempos presentes, lo que supone promover un aprendizaje de la convivencia política desde el sentido y el cuidado del otro (Bárcena y Melich, 2000).

- La necesidad de concebir el pasado reciente como fondo de experiencia de nuestra existencia social pasada y presente. La demanda de constituir una memoria cívica del pasado reciente que fortalezca una identidad que nos permita afirmar un nosotros hemos vivido supone promover un aprendizaje sobre nuestra identidad como comunidad temporal de sentido.

- La necesidad de incorporar la enseñanza de los DDHH desde una perspectiva histórica y vital como fuente de reflexión permanente de la condición de la ciudadanía. Un aprendizaje de la problematización de la experiencia como palabra y responsabilidad ética.

La propuesta de una pedagogía de la memoria vista así tiene sus fundamentos en fuentes hermenéuticas críticas y narrativas. Desde su consideración hermenéutica, se

29 Véase Osorio y Rubio (2007), en donde se propone la aproximación al mundo como espacio de experiencia, en donde es posible integrar experiencias pedagógicas críticas asociadas a la reflexividad la narrativa y los indicios como orientaciones para una mirada pedagógica-investigativa de la experiencia. Ver la síntesis historiada que ha definido la relación entre pedagogía y ciudadanía a lo largo del siglo XX como una competencia histórica, un proceso de construcción de identidades colectivas, una acción de proximidad a las víctimas, un espacio de formación crítica y creación de capacidades, así como una Pedagogía de la diferencia. Ver también Osorio (2009). 
vislumbra la historicidad de la ciudadanía, para considerarla en relación con nuestra historia (tiempo largo y corto), proveyéndonos de experiencias, formas, creaciones, reediciones, proyectos inconclusos y fracasos. Se enfatizan las herencias de que somos portadores y las responsabilidades que emergen a partir de la comprensión de dichos procesos. El trabajo hermenéutico crítico (Ricoeur, 2004) considera que el pasado reciente (como forma discursiva) debe ser confrontado con el propio presente, sus demandas y la comunidad que delibera de ello, por lo cual su comprensión no se ordena de cara al pasado sino hacia el futuro. Ello supone:

- Promover la reflexión y aprendizaje sobre la condición histórica de la ciudadanía

- Promover la reflexión y aprendizaje sobre la experiencia del pasado reciente; su significado, herencia, continuidades, discontinuidades y su genealogía a la luz de la demanda del presente integrando el sentido de la responsabilidad y de la deuda.

Desde las consideraciones críticas, se reflexiona sobre las propuestas que han vinculado modernidad y educación, recuperando a ésta última como una esfera pública y relevando el recuerdo del pasado reciente como una acción política para liberar la memoria de las determinaciones impuestas por los discursos políticos construidos. Esto supone que:

- El recuerdo de la experiencia del pasado reciente es una referencia pública que evidencia un conflicto de memorias frente al cual el discurso político oligárquico vigente ha procurado su clausura. El discurso hegemónico encubre intereses que legitiman en clave narrativa el presente y las condiciones de desigualdad de las ciudadanías en relación con el derecho de recordar. Ante ello, promueve el desmontaje crítico del discurso hegemónico.

- Las políticas de la memoria no son la única esfera pública ordenadora de la producción del recuerdo. En congruencia con la experiencia de pérdida y daño, se promueve la integración de la política de la memoria oficial con el recuerdo como una demanda moral de escucha y formación ciudadana.

- Los docentes que ejercen la enseñanza del pasado reciente son los defensores de futuro. Recupera la utopía como la dialéctica entre el acto de denunciar la estructura deshumanizante y el acto de anunciar la estructura humanizadora (Freire citado en Silva, 2001; en línea), defiende la libertad como carta de ciudadanía y la necesidad de una educación moral abierta a lo humano, que reconozca al sujeto y a la comunidad como un proceso en construcción. ${ }^{30}$ Por ello, se destaca la importancia de la enseñanza del juicio crítico sobre el pasado reciente como un eje de la formación de una capacidad rememorativa (crítica, moral y afectiva) de los hechos y las experiencias para la construcción de una memoria cívica. ${ }^{31}$ Desde la narrativa, se reconoce que el camino para recuperar la experiencia del pasado reciente está mediado por el relato, la palabra y la memoria, ${ }^{32}$ y que la misma narración se presenta como condición de vínculo ínter subjetivo para conocer y recordar. Ello supone que:

- La experiencia del pasado puede ser recuperada a través de la narración. En cada momento en que se procure su evocación se movilizan, experiencias y memorias que

30 Al respecto, los aportes de Ricoeur respecto de la identidad como ipseidad y los de la acción y acontecimiento como natalidad reorientan las perspectivas modernas clásicas que orientan el estudio del sujeto y de la acción en la historia.

31 La noción de justicia compartida (Ralws), no asegura el arrepentimiento por la violencia cometida, ni genera identidad común. Ver Kymlicka y Wayne (1997; en línea).

32 La historia se ha ajustado a un discurso historicista que bloquea el vínculo intersubjetivo con el propio pasado. 
deben ser escuchadas y orientadas para acoger las memorias del duelo, la pérdida y del dolor, promoviendo aprender a sentir con el otro.

- La imaginación moral sobre los actos presentes en el relato puede propiciar la reflexión compasiva sobre los otros (Ginzburg, 2001), posibilitando aprender que, ante la irreversibilidad de los hechos, existe una posibilidad para evitar el daño. La narración del pasado reciente permitirá movilizar las emociones hacia las palabras, abiertas al otro, aprender la acogida del otro. En definitiva, una imaginación moral que enseña a deliberar con el sentimiento.

\section{LO PROPIO Y LOS LÍMITES DEL EJERCICIO DE UNA PEDAGOGÍA DE LA MEMORIA}

La pedagogía de la memoria que postulamos, como una acción estratégica para contribuir a la formación de una ciudadanía como cristalización de memoria, aspira a abrir la palabra a los tiempos del pasado reciente para que los jóvenes puedan acrecentar su disponibilidad de experiencia social compartida. Una pedagogía de la memoria situada en estos marcos debería abrir nuevas tramas de posibilidad; revertir el orden formal del tiempo; dialogar críticamente con los relatos de la Historia; cuestionarse sobre los futuros prescritos; contrastarlos desde la contingencia con los deseos volviendo su mirada al pasado para recuperar proyectos inconclusos, lo no dicho y lo olvidado. Estas acciones permitirían abrir presente que ha sido definido por un solo discurso.

La pedagogía de la memoria en su acto de narración del Pasado Reciente propone habitar un mismo relato. Es una acción que implica una negociación entre la memoria historiográfica, la memoria del pedagogo y la de los otros. Dicha narración, no puede dar origen a una memoria impuesta-normativa de la violación de DDHH ello generaría una nueva sumisión perversa. La enseñanza del pasado reciente debe abrirse a una conversación, en la cual el límite de su amplitud y connotación es el otro.

La integración entre memoria e historia es un desafío en tanto el espesor cultural del presente neoliberal lo impide. La historia del pasado reciente se encuentra como un fondo de experiencia por abrir como vivencia social acontecida y narrable. Quien enseña el pasado reciente desde esta perspectiva, debe enfrentar, por un lado, el pensamiento oligárquico vigente que banaliza la experiencia del pasado, desvinculando a quienes violaron los DDHH de sus acciones y acontecimientos históricos, aduciendo un oportunismo relativista ("Cualquiera pudo hacerlo"). Y, por otro, debe enfrentar su clausura a través del discurso presentista modernizador y naturalizador que bloquea toda capacidad de pensamiento. Por ello, la pedagogía de la memoria es una acción cultural crítica que realiza un conjunto de desplazamientos que la sitúan en un lugar propio; desplaza el recuerdo desde los conceptos disciplinares de la historia hacia la memoria como categoría ético política reflexiva y realiza un desplazamiento pedagógico al validar la experiencia como fuente de palabra para narrar el recuerdo. Considera la vida cotidiana como una relación entre los procesos macro y micro sociales en la cual pueden cristalizar las contradicciones sociales y en donde es posible vislumbrar su expresión subjetiva. Se asume la perspectiva del continuum de la política que se desarrolla en el contexto pedagógico- escolar (Lechner, 2006). Por ello, la pedagogía de la memoria, a través de un acto comunicacional, puede provocar el recuerdo como una estrategia para actuar en dicha relación. Provocar el 
recuerdo del pasado reciente supone, por un lado, salirse del presente fáctico y debilitar los discursos dominantes instalados y, por otro, propiciar la imaginación moral para dar cabida al pasado humano silenciado. La enseñanza del pasado reciente se sitúa así en un diálogo crítico con el código disciplinar que rige la enseñanza de la historia como un legado cultural no negociable con otras ciencias sociales (Cuesta, 2007). El conocimiento histórico vigente en las aulas se ha caracterizado por una desvitalización y extrañamiento social clasista. ${ }^{33}$ Valga para la enseñanza de nuestro pasado reciente y sus reminiscencias oligárquicas, liberales y las orientaciones disciplinares presentes en los programas de enseñanza. La desvinculación y desvitalización se promueve a través de el encadenamiento historicista del relato del pasado reciente vigente que termina por argumentar la defensa de la democracia y de los gobiernos de la concertación como oposición a la dictadura (la historia de los vencedores, la de los gobernantes de turno); desvincula a los jóvenes de la vida de los ciudadanos que experimentaron el dolor del cuerpo, lo que remite el sufrimiento y las prácticas de exterminio y discriminación a un espacio de lo inombrado y elimina a la ciudadanía como categoría política, excluyéndola de las tesis explicativas de la crisis republicana. En ese sentudo, se escinde la representación de la vida social de su proyecto y deseos inconclusos y expectativas, lo que transforma la Historia en un encadenamiento de hechos e integra la enseñanza de los DDHH como una imposición normativa ajena a la vida.

La pedagogía de la memoria del pasado reciente debe vincular deseo y conocimiento como fuente de imaginación ciudadana. Para poder desarrollar este propósito, se requiere validar la experiencia social del pasado reciente como fuente de constitución subjetiva de la ciudadanía. Para ello se debe:

- Abrir los códigos de los cercos disciplinares al vínculo con la vida (la experiencia y sus sedimentaciones emotivas y conceptuales).

- A través de un camino de reflexión hermenéutica, dar paso a un vínculo histórico (memoria, historia y política), propiciando espacios de aprendizaje en los que sujetos conozcan a los otros históricamente situados y construyan su crítica desde el presente hacia el pasado por sus efectos de silencios y ausencias.

- Considerar el futuro en la crítica. No es posible pensar el pasado desde sus efectos sin pensar un mañana. La crítica se orienta hacia el desmontaje de las tesis explicativas y articulaciones conceptuales construidas para encriptar ese pasado y desde su genealogía histórica da cuenta de cómo se ha ido estructurando cada una de las tesis explicativas sobre la crisis del pasado reciente para consolidar una estructura de poder contingente que termina por afianzar el carácter oligárquico de la simbolización política.

- Integrar la narrativa. Ella nos permite, por un lado, sentir lo humano, y establecer un vínculo rememorativo activo con quienes recordamos pudiendo abrir una razón ajustada del recuerdo. ${ }^{34}$

33 Ver Cuesta (2007). La presencia en los programas de algunas de las tesis explicativas y categorías articuladoras ya descritas evidencian en su base social de construcción, una negociación de carácter elitista entre los sectores más conservadores de la política y los representantes de los gobiernos de la concertación.

34 Ver el término razón ajustada como contraposición a la ética (Universal) en Reyes Mate (2008), texto en el que se realiza una ruptura con los códigos disciplinares y con el campo práctico de la pedagogía del pasado reciente, el que hasta ahora no ha definido una visión particular de la enseñanza del pensar histórico, quedando sujeto a las competencias vitales del docente en ejercicio. 
Quien enseña el Pasado Reciente es conciente de los límites de esta pedagogía, las resistencias a la memoria crítica y los cercos epistemológicos existentes; pero sabe también, de las potencialidades de los nuevos relatos y de la palabra. Por ello, apuesta a aquello que está delante del texto, lo que se ha escrito sobre este pasado y lo que no se ha dicho de él y la comunidad que recibe y puede observar críticamente estas herencias. Desde el presente en que vivimos y frente al texto, provoca el acontecimiento, evoca el pasado, propicia un nuevo silencio sutil y piensa el futuro.

Enseñar el pasado reciente desde esta perspectiva supone asumir responsablemente sus límites. Al enseñar nuestro pasado, se debe romper un cerco epistemológico y el discurso político que cruza transversalmente nuestra sociedad y las aulas. La apuesta a la comprensión del texto del pasado, pensar sobre cómo se ha elaborado y narrado como un argumento para la comprensión de nuestro presente, permite pensar nuestro pasado como espacio de discusión abierto a una comunidad que puede volver a mirar desde su propia contingencia lo que sucedió y lo que no sucedió. Enfatizar el giro hacia la memoria crítica, desplazar el interés de los jóvenes hacia lo que no está y puede ser abordado a través del camino de la representación, exige dos consideraciones de reflexión; por un lado, los límites que puede alcanzar este provocar el acontecimiento, esto es, "reconstruir" (críticamente) el hecho de violación de DDHH, y por otro, reconocer el quiebre de la vida republicana como objeto de reflexión, atendiendo a la búsqueda de lo no dicho de la experiencia.

Se agrega a lo dicho un límite ético: si bien abogamos por una enseñanza que se sustente en la comprensión y la narrativa, no podemos asegurar que todos los jóvenes actuales se dispondrán a desarrollar un recuerdo crítico. En ese sentido, desde lo que está frente al texto, cobra mayor relevancia el vínculo político que describe la memoria del pasado reciente, en tanto dicho recuerdo reconstruido actúa como fuerza movilizadora a la vez que reveladora del estado de la comunidad a la cual se dirige. La activación del recuerdo permite develar qué capacidades ciudadanas se presentan vivas en nuestros jóvenes. Desde allí, reconociendo que no es posible imponer el sentimiento, pero sí promover la comprensión a través del recuerdo, pedagógicamente y contextualmente, quien enseña el pasado reciente sin ingenuidad, provoca el acontecimiento desde la narración, introduce el pasado de dolor y fractura de la comunidad en el presente, abriendo espacios para que emerja en ese proceso la comunidad actual y la posible. ${ }^{35}$

\section{REFERENCIAS BIBLIOGRÁFICAS}

Agamben, G. (2004). Estado de excepción. Homo sacer II, 1 Valencia: Pre-textos.

Allamand, A. (2005). El impacto de las ideologías en el respeto de los Derechos Humanos en el siglo XX. Estudios Públicos, n.97.

Aróstegui, J. (2006). Memoria y revisionismo. El caso de los conflictos españoles del siglo XX. Cuadernos de Pedagogía, n362, p54-58.

Bárcena, F. Y Melich, J.C. (2000). La educación como acontecimiento ético. Natalidad, Narración, Hospitalidad. Barcelona: Paidos.

35 La enseñanza del pasado reciente no puede sustentarse en respuestas monocausales frente a su gestión cuando se debe responder a los problemas complejos de presente. Ver Franco y Levin (2006; en línea). 
Bengoa, J. (1996). La comunidad perdida. Ensayos sobre identidad y cultura. Ediciones Sur. Santiago. Calveiro, P. (2008). La memoria como futuro. Revista Actuel Marx: En Memorias en busca de Historia.

Cuesta, R. (2007). Los deberes de la memoria en educación. España: Ministerio de Educación y Ciencia (MEC).

Donoso, M. et al. (2003). Historia y Ciencias Sociales 2 educación media. Santiago: Editorial Santillana.

Franco, M. Y Levin, M. (2009). La historia reciente en la escuela. Nuevas preguntas y algunas respuestas. Red Interdisciplinaria de Estudios sobre Historia Reciente. Publicación original en Novedades educativas, n. 202. En línea; disponible en http://www.riehr.com.ar/archivos/Educacion/Novedades $\% 20$ Educativas\%20La\%20historia\%20reciente\%20en\%201a\%20escuela.pdf

Garcés, M. Y Leiva, S. (2005) El golpe en la legua. Los caminos de la historia y la memoria. Santiago. LOM

Ginzburg, C. (2001). Ojazos de madera. Nueve reflexiones sobre la distancia. Barcelona: Editorial Península.

Kymlicka, W. Y Wayne, N. (1997). El Retorno del ciudadano. Una revisión de la producción reciente en teoría ciudadana. Ágora, n. 7, 5-42. En línea; disponible http://www.cholonautas. edu.pe/modulo/upload/kymlick.pdf

Kosseleck, R. (1993.). Futuro Pasado para una semántica de los tiempos históricos. Barcelona. Paidos.

Lechner, N. (2007). Obras escogidas. Vol. 2.Colección Pensadores Latinoamericanos. Santiago. LOM. .(1998). Nuestros miedos. Conferencia Inaugural en la Asamblea General de FLACSO, México publicada en Perfiles Latinoamericanos 13, FLACSO-México. 1-19. En línea; disponible en http://www.desarrollohumano.cl/extencion/miedos.pdf

Lefranc, S. (2003). "Aquello que no se conmemora. ¿Democracias sin un pasado compartido?" Rev. Cienc. Polit., v.23, n.2, 231-240.

Lira, E. Y Loveman, B. (2002). El espejismo de la reconciliación política. Chile 1990-2002. Santiago. LOM.

MINEDUC. 2012. "La búsqueda del desarrollo económico y de la justicia social". Unidad 5: El siglo XX: Marco curricular. 69-70.

Mudrovic, M.E. (2005). Historia, narración y memoria. Los debates actuales en filosofía de la Historia. Madrid: Akal.

Palieraki, E. Torrejon, C. (2008). Historiadores: ¿Portavoces de la memoria? Reflexiones sobre los límites y usos de la memoria en las historiográficas chilena y francesa En Memorias en busca de Historia. Actuel Marx, n. 6, 27-46.

Osorio, J. Y Rubio, G. (2007) La cualidad enfoque indicial en educación. Santiago.Escuela de Humanidades y Política.

- (2006). El Deseo de la Memoria. Escritura e Historia. Santiago: Escuela de Humanidades y Política.

Osorio, J. (2009). La modernidad educativa en cuestión: hacia una pedagogía ciudadana. Mimeo autor.

Perotin-Dumon, A. (Dir). (2007). Historizar el pasado vivo. En línea; disponible en http://etica. uahurtado.cl/historizarelpasadovivo/es_contenido.php

Reyes, L. (2004). Actores, conflicto y memoria: reforma curricular de historia y ciencias sociales en Chile, 1990-2003" (pp. 65-93). En Jelin, E. y Lorenz, F. (Comp.), Educación y Memoria: La escuela elabora el pasado. Buenos Aires: Siglo XXI

Reyes Mate, M. (2008). La herencia del olvido. Madrid: Edit Errata naturae.

Ricoeur, P. (2004). La Historia la memoria y el Olvido. Buenos Aires: FCE 
Ruiz Torres, P. (2007). Los discursos de la memoria histórica en España. HISPANIA NOVA. Revista de Historia Contemporánea, n.7, 5-30. En línea; disponible en http://hispanianova.rediris.es http://hispanianova.rediris.es/7/dossier/07d001.pdf

Silva, V. (2006). Emergencias micro históricas y la ampliación de las temporalidades: de Walter Benjamin al postcolonialismo. Mimeo

Silva, JC. (2001). Ciudadanía: entre el debate crítico, la lucha política y la utopía. Ultima décad., vol.9, n.14, 91-111. En línea, disponible en:<http://www.scielo.cl/scielo.php?script=sci_ arttext\&pid=S0718-22362001000100006\&lng=es\&nrm=iso>. ISSN 0718-2236. doi: 10.4067/ S0718-22362001000100006.

Wilde, A. (1999). Irrupciones de la memoria: la política expresiva en la transición a la democracia en Chile. En Pérotin-Dumon, A. (DIR), Historizar el pasado vivo. En línea; disponible en http:// etica.uahurtado.cl/historizarelpasadovivo/es_contenido.php 